\title{
ARTÍCULO 32
}

\section{"Enmiendas}

1. La OISS recopilará las propuestas de enmiendas al Convenio que presenten los Estados Parte para los que esté vigente y a solicitud de tres de ellos, por medio de las respectivas Autoridades Competentes o pasados tres años, convocará a una Conferencia de Partes para su tratamiento.

2. Toda enmienda aprobada por la Conferencia de Partes estará sujeta a ratificación, aceptación o aprobación por los Estados Parte.

3. Toda enmienda refrendada de conformidad con los apartados 1 y 2 del presente artículo entrará en vigor respecto de un Estado Parte noventa días después de la fecha en que éste deposite en la Secretaría General Iberoamericana, a través de la OISS, el instrumento de ratificación, aceptación o aprobación de esa enmienda.

4. Cuando una enmienda entre en vigor, será vinculante sólo para los Estados Parte que hayan expresado su consentimiento al respecto. Los demás Estados Parte quedarán sujetos a las disposiciones del presente Convenio, así como a cualquier otra enmienda anterior que hubiesen ratificado, aceptado o aprobado.

\section{JOSÉ ANTONIO IGLESIAS CÁCERES NATALY RODRÍGUEZ BESSIO}

Docentes de Derecho del Trabajo y de la Seguridad Social

Facultad de Derecho, Universidad de la República, Uruguay 


\title{
RESUMEN
}

El artículo 32 establece un procedimiento para la recepción de enmiendas por los Estados Parte, y la convocatoria de la Conferencia de Partes; a su vez, también refiere a la ratificación, aceptación o aprobación de aquella enmienda aprobada por la Conferencia de Partes, al plazo para su vigencia y a la vinculación de la misma.

PALABRAS CLAVES: Ratificación, aceptación, aprobación, adhesión, enmienda.

\begin{abstract}
Article 32 establishes a procedure for the reception of amendments by the Member States and the call to the Stakeholders Conference. It also refers to the ratification, acceptance or approval of amendments approved by the Stakeholders Conference, the period for their validity and how they compel each Member State.
\end{abstract}

KEYWORDS: Ratification, acceptance, approval, adhesion, amendment. 
SUMARIO

I. ARTÍCULO 32 INCISO PRIMERO

II. ARTÍCULO 32 INCISO SEGUNDO

III. ARTÍCULO 32 INCISO TERCERO

IV. ARTÍCULO 32 INCISO CUARTO

V. BREVES CONCLUSIONES

\begin{tabular}{llllllllll}
\hline \hline e-Revista & Internacional de la Protección & Social, & ISNN & $2445-3269$. & 2017, & Vol. & II, & $N^{\circ} 1$
\end{tabular} 


\section{ARTÍCULO 32 INCISO PRIMERO}

La norma general para la enmienda de tratados multilaterales es que pueden ser modificados por acuerdo de Partes, conforme a lo dispuesto por la Convención de Viena de 1969. En cuanto a las reglas aplicables para ello, dicho instrumento rige en caso que el tratado no disponga otra cosa (artículo 39 de la Convención de Viena) ${ }^{1}$.

El artículo 32 del Convenio Multilateral Iberoamericano de Seguridad Social establece en su primer inciso que la Organización Iberoamericana de Seguridad Social recopilará las propuestas de enmiendas al Convenio que presenten los Estados Parte para los que está vigente y a solicitud de tres de ellos, por medio de las respectivas Autoridades Competentes o pasados tres años, convocará a una Conferencia de Partes para su tratamiento.

De esta forma el Convenio modifica el sistema propuesto por la Convención de Viena, debido a que establece un sistema centralizado en la Organización Iberoamericana de Seguridad Social.

\section{ARTÍCULO 32 INCISO SEGUNDO}

El inciso segundo establece que toda enmienda aprobada por la Conferencia de Partes estará sujeta a ratificación, aceptación o aprobación por los Estados Parte.

De este inciso se desprende claramente que una vez aprobada la enmienda por la Conferencia, ésta no tiene vigencia inmediata, sino que requiere necesariamente para su efectividad de la ratificación, aceptación o aprobación por los Estados Parte.

\section{ARTÍCULO 32 INCISO TERCERO}

El inciso tercero establece que toda enmienda refrendada de conformidad con los apartados 1 y 2 del artículo 32 entrará en vigor respecto de un Estado Parte noventa días después de la fecha en que éste deposite, en la Secretaría General Iberoamericana a través de la Organización Iberoamericana de Seguridad Social, el instrumento de ratificación, aceptación o aprobación de esa enmienda.

Tal cual lo establece este inciso tercero, no basta con la ratificación, aceptación o aprobación de la enmienda por un Estado Parte, sino que se va a requerir para su entrada en vigor que transcurra un plazo de noventa días después que la misma se deposite en la Secretaría General Iberoamericana, a través de la Organización Iberoamericana de Seguridad Social.

Se busca con ello dar mayores garantías a los Estados Parte, así como el tiempo necesario para procesar los eventuales ajustes en la aplicación del Convenio.

\footnotetext{
${ }^{1}$ VII Premio ISS. Estudio sobe el Convenio Multilateral Iberoamericano de Seguridad Social. 2012; p. 111.

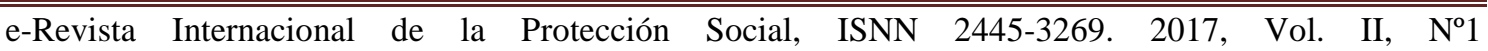
http://dx.doi.org/10.12795/e-RIPS.2017.i01.10

Página 74
} 


\section{ARTÍCULO 32 INCISO CUARTO}

Finalmente, el inciso cuarto establece que cuando una enmienda entra en vigor será vinculante sólo para los Estados Parte que hayan expresado su consentimiento al respecto.

Los demás Estados Parte quedarán sujetos a las disposiciones del Convenio Multilateral Iberoamericano de Seguridad Social, así como a cualquier otra enmienda anterior que hubiesen ratificado, aceptado o aprobado.

Respecto de este artículo 32 en particular, debemos decir que a la fecha según datos proporcionados por la Secretaría General Iberoamericana no se ha formulado ninguna enmienda al Convenio Multilateral Iberoamericano de Seguridad Social. Ni tampoco se ha planteado ninguna controversia entre los Estado Parte en los términos referidos en el mismo.

Las lógicas diferencias de interpretación entre los Estado Parte se han planteado y, en la medida de lo posible resuelto en el seno del Comité Técnico Administrativo del Convenio, que hasta la fecha se ha reunido presencialmente en siete ocasiones y creado en su seno tres comisiones (jurídica, informática y de gestión), en las que se han suscitado y debatido las distintas cuestiones planteadas, esencialmente referidas a los procesos de gestión.

\section{BREVES CONCLUSIONES}

En definitiva, el presente Convenio modifica el sistema propuesto por la Convención de Viena, debido a que establece un sistema centralizado en la Organización Iberoamericana de Seguridad Social.

Se establece claramente que una vez aprobada la enmienda por la Conferencia, ésta no tiene vigencia inmediata, sino que requiere necesariamente para su efectividad de la ratificación, aceptación o aprobación por los Estados Parte.

A su vez se busca dar mayores garantías a los Estados Parte, así como el tiempo necesario para procesar los eventuales ajustes en la aplicación del Convenio.

Finalmente, las lógicas diferencias de interpretación entre los Estado Parte se han planteado y, en la medida de lo posible, resuelto en el seno del Comité Técnico Administrativo del Convenio, no habiéndose formulado a la fecha ninguna enmienda al Convenio Multilateral Iberoamericano de Seguridad Social.

\begin{tabular}{llllllllll}
\hline \hline e-Revista & Internacional de la Protección & Social, & ISNN & $2445-3269$. & 2017, & Vol. & II, & N $^{\circ} 1$
\end{tabular} 